\title{
Introduction to Trauma-Informed Practices for Mental Health and Wellness in Urban Schools and Communities
}

\author{
Malik Henfield ${ }^{1} \cdot$ Ahmad Rashad Washington $^{2} \cdot$ Zina Besirevic $^{3} \cdot$ Lisa De La Rue $^{3}$
}

(c) Springer Nature B.V. 2019, corrected publication 2021

Data has revealed that consistent exposure to trauma, whether that trauma is simple (one occurrence or acute) or complex (repeated consistent exposure), has deleterious impacts on school-aged children's sense of safety, their sense of school belonging, self-confidence, academic performance and social relationships (Bath 2008; Brunzell et al. 2016). Because these domains are foundational to students' holistic wellness and academic performance, the need to intervene and eradicate trauma exposure, and its varied ecological sources, is indisputable. Traditionally, trauma informed care has focused on providing students with the necessary skills to manage the psychosocial and emotional turmoil brought about by trauma (e.g., familial neglect, physical violence, sexual assault and sexual abuse). Pragmatically, then, trauma informed care has, dissiminating entailed strategies for lessening the impact of trauma. As important as these strategies are, this approach often minimizes or neglects, altogether, a serious consideration for the sociological antecedents of trauma and its attendant psychosocial consequences (Malott and Schaefle 2015; Williams 2013).

In the contemporary moment, it feels incomprehensible to divorce operational definitions of trauma from the current sociopolitical landscape. It feels dishonest and disingenuous for conversations about trauma and trauma informed care to occur without considering how racism and other forms of social oppression pervade social

Ahmad Rashad Washington

arwash04@louisville.edu

Malik Henfield

Mhenfield@1uc.edu

Zina Besirevic

zina.besirevic@gmail.com

Lisa De La Rue

ldelarue@usfca.edu

1 School of Education, Loyola University of Chicago, Chicago, USA

2 Department of Counseling and Human Development, College of Education and Human Development, University of Louisville, Louisville, USA

3 University of San Francisco, San Francisco, USA 
systems and institutions (e.g., juvenile justice, K-16 educational pipeline) where marginalized students are habitually exposed to forms of psychological and physical trauma (Crosby 2016; Quiros and Berger 2015).

For instance, we have recently witnessed several blatant examples of psychological and physical trauma directed towards stigmatized, vulnerable and historically marginalized groups and communities. Across social media platforms, gut-wrenching videos of inhumane treatment towards undocumented immigrants to this country epitomize trauma. One video, captured the excruciating emotional and psychological trauma experienced by young Latinx girls and boys as their parents were corralled, detained, and ushered away by Immigration Customs Enforcement (ICE) without any elaboration as to their destination or when they would be reunited. In the news, we read stories about how Latinx students have to negotiate schools where blatant acts of vitriol and intolerance are enacted by white students. One especially disturbing incident occurred in California when students from a majority Latinx high school in Orange County were confronted with "Build the Wall" and "We Love White" banners that were unfurled during a football game. Similarly, vicarious media exposure to examples of anti-Black police brutality has tangible impacts on Black students. In Minnesota, even though it has been two years since Philando Castile was killed by a Minnesota police officer, students at the school where he was employed as a cafeteria supervisor are still adjusting to his profoundly graphic death. Though these incidents occurred at different times and locations, the traumatizing impact they have on racialized students has to be seriously considered and cannot be underestimated or denied.

The realization that exposure to trauma is, in large measure, the result of a confluence of ideologies (e.g., racism, heteropatriachy) that disproportionately impact systematically marginalized students was the major impetus for this special issue. The pieces in this special issue reflect a genuine commitment and desire, from the editors and authors, to contribute a more nuanced and layered analysis to the contemporary trauma and trauma informed discourse, particularly in relation to urban education. In their study, Bentley-Edwards, Smith, Robbins and Adams-Bass draw our attention to the ways Black college students' deep and meaningful immersion with other Black students, in social and extracurricular activities, can protect against violence exposure and victimization. Their findings offer culturally relevant suggestions for university-based counseling professionals (e.g., retention counselors) working with Black students exposed to violence. Utilizing a participator action research methodology and an ecological-feminist-Latinx framework, Mayorga and Rosales highlight the ways Latinx high school and college students, using critical theoretical frameworks, interrogate issues impacting their communities. Next, in recognizing how racialized girls (e.g., Black, Latinx, Native American) are relegated to the margins of the trauma informed care discourse, Crosby centers these girls' experiences and explores whether trauma-informed school settings produce significant changes in trauma symptomology, and if these changes vary by race. In her systematic review of the social emotional learning (SEL) literature base, Barnes reveals several egregious shortcomings, namely the underrepresentation of culturally responsive interventions and a lack of scholarship that examines the realities of how racism reverberates in racialized students' lives. Through youth participatory action research 
(YPAR), Desai discusses how resilient youth negotiate the toxic juvenile justice system. In the concluding article, Martinez incorporates insights from various critical pedagogical frameworks to conceive "Compa Love", "a framework that enables us to practice love as an intervention to trauma within the context of urban classrooms." As editors, we could not be more excited about the publication of the compiled articles. Collectively, these articles comprise a special issue of Urban Review that makes a much-needed intervention in the way trauma is conceptualized. Specifically, the authors in this special issue provide suggestions for confronting sources of trauma (e.g., institutional racism) that are often undertheorized and infrequently considered in the trauma informed discourse.

\section{References}

Bath, H. (2008). The three pillars of trauma-informed care. Reclaiming Children and Youth, 17, 17-21.

Brunzell, T., Stokes, H., \& Waters, L. (2016). Trauma-informed positive education: Using positive psychology to strengthen vulnerable students. Contemporary School Psychology, 20, 63-83.

Crosby, S. D. (2016). Trauma-informed approaches to juvenile justice: A critical race perspective. Juvenile and Family Court Journal, 67, 5-18.

Malott, K. M., \& Schaefle, S. (2015). Addressing clients' experiences of racism: A model for clinical practice. Journal of Counseling \& Development, 93, 361-369.

Quiros, L., \& Berger, R. (2015). Responding to the sociopolitical complexity of trauma: An integration of theory and practice. Journal of Loss and Trauma, 20, 149-159.

Williams, M. T. (2013). Can racism cause PTSD? Implications for DMS-5. Psychology Today, 20. Retrieved August 17, 2019 from https:/www.psychologytoday.com/us/blog/culturally-speaking/ 201305/can-racism-cause-ptsd-implications-dsm-5.

Publisher's Note Springer Nature remains neutral with regard to jurisdictional claims in published maps and institutional affiliations. 